\title{
Microwave Assisted Batch Sterilization of Apple Juice
}

\author{
M.M. Pragalyaashree, D. Tiroutchelvame, S. Gokularaman
}

\begin{abstract}
A study was carried out to determine the effect of microwave exposure time and power level on the destruction of E.coli and yeast in apple juice. The locally procured apple juice was subjected to microwave treatment of power level 180-900W for various time duration of 20-100s. The time and power level parameters of the microwave were optimized based on the inactivation of the microorganisms present in the juice. E.coli was found to be inactivated at $90 \mathrm{~s}$ with $900 \mathrm{~W}$ power. Yeast was completely inactivated at $60 \mathrm{~s}$ with $450 \mathrm{~W}$ power level. The results of inactivation were modeled using GInafit software. Among the various models, Weibull model and Double Weibull model were found to be the best fit for E.coli and yeast, respectively. Nutrient content of the fresh and microwave treated juice were analyzed for total sugar, reducing sugar, total soluble solids and ascorbic acid content. It was inferred from the results that there was no nutrient loss in the post treated samples whereas, the ascorbic acid content decreased considerably.
\end{abstract}

Keywords: Ascorbic acid, E.coli, Inactivation, Microwave sterilization, Yeast

\section{INTRODUCTION}

Safety of fresh juice is an important attribute for consumption. With the increasing concern on food safety, there arises a need of enhancing microbial food safety and quality without affecting the nutritional and organoleptic characteristics of food. The advancement in food processing technology has led to various methods to ensure the safety of the food. Many preservation techniques have been developed in the past for improving the quality and safety of food. Modern techniques of thermal processing such as microwave, ohmic, radio frequency heating were explored in detail [1]. The above technology can be adopted alone or in combination to various food materials. Ohmic heating is an advanced thermal processing method in which the food material serve as an electrical resistor, is heated by passing electricity through it. Electrical energy is dissipated into heat which results in rapid and uniform heating[2].The technology of microwave processing is mainly used for blanching, pasteurization, sterilization, baking, drying, cooking, etc.[3],[4].

Revised Manuscript Received on December 30, 2019.

* Correspondence Author

Dr.M.M.Pragalyaashree*, Assistant Professor, Department of Food Processing Technology, Karunya Institute of Technology and Sciences, Coimbatore, Tamilnadu, India. Email: shreepragalyaa@gmail.com

Dr.D.Tiroutchelvame, Assistant Professor, Department of Food Processing Technology, Karunya Institute of Technology and Sciences, Coimbatore , Tamilnadu, India.. Email: tirou2011@gmail.com

S.Gokularaman, Former M.Tech.student, Department of Food Processing Technology, Karunya Institute of Technology and Sciences, Coimbatore, Tamilnadu, India..

(c) The Authors. Published by Blue Eyes Intelligence Engineering and Sciences Publication (BEIESP). This is an open access article under the CC-BY-NC-ND license http://creativecommons.org/licenses/by-nc-nd/4.0/
Many researchers have confirmed that the destruction of microorganisms is solely due to thermal effect whereas few research findings have reported the microbial inactivation by non-thermal effects. The non-thermal effects of microwave was developed by Kozempel et al.(1998)[5]. The system was operated at a power range of $5-5.4 \mathrm{~kW}$, (multiple passes through a microwave generator), flow rate of 0.96 to 1.26 $\mathrm{kg} / \mathrm{min}$ with a retention time 1.1 to $1.5 \mathrm{~min}$ per pass. To achieve the non-thermal effect of microwave, thermal energy was removed by a cooling tube within the process line in the microwave generator to maintain the temperature below $40^{\circ} \mathrm{C}$.

The potential factors such as depth of penetration and quicker rate of heating of microwave results in improved retention of thermo labile constituents present in liquid foods like, milk and fruit juices [6]. The inactivation of enzymes and destruction of microorganisms present in fruits and fruit juices (citrus fruits), during microwave pasteurization has not been studied thoroughly. Copson (1962) [7] reported that the enzyme pectin methyl esterase (PME) in orange juice concentrate could be inactivated at $66^{\circ} \mathrm{C}(580 \mathrm{~W})$.

The distribution and uniformity of electromagnetic field is greatly influenced by the design and operating frequency of the microwave cavity, size, shape, placement, and dielectric properties of food [8], [9]. The major challenge in microwave heating of food is the edge overheating effect. This effect is caused when the electric field parallel to the edge of the food and considered as a non-resonant phenomenon.

The objectives of this study were to find the optimum exposure time for the inactivation of microorganisms in fresh apple juice using microwave and to determine suitable power level of microwave, to develop models and to analyze the nutrient parameters of the fresh and microwave treated juice.

\section{MATERIALS AND METHODS}

\section{A. Collection of fresh apple juice sample}

Freshly prepared apple juice samples were purchased from a fruit juice shop near Karunya Nagar, Coimbatore, Tamilnadu, India and was used for the experiment.

\section{B. Preparation of growth medium}

Microorganisms require a suitable environment for their growth. Every nutrients including the carbon source, nitrogen source and required growth supplements is to be supplied to the microorganisms to grow and survive. In order to satisfy the nutrient requirements of the microorganisms, nutrient agar medium was prepared at a concentration of $40 \mathrm{~g} / \mathrm{L}$. Nutrient agar being a general media will provide suitable environment for the growth of all microorganisms present in the sample. In order to differentiate the different microorganisms present in the apple juice sample selective media were prepared. 


\section{Microwave Assisted Batch Sterilization of Apple Juice}

Selective media allow the growth of only the specific microorganisms.

From the literature review it was clearly found that apple juice is prelevant of E.coli and yeast. Therefore, Mac conkey agar and Yeast glucose chloramphenicol agar were prepared as these are selective media for E.coli and Yeast respectively at a concentration of $40 \mathrm{~g} / \mathrm{l}$.

\section{Sterilization of the materials}

Cross contamination is a major problem in any microbiological research. In order to avoid these contaminations, the materials used for the work were sterilized using autoclave at a temperature of $121^{\circ} \mathrm{C}$ and 15 bar pressure for 20 minutes. All the materials including the prepared media, empty petriplates, test tubes, beakers and conical flask were autoclaved.

\section{Microbial Analysis}

The quality of the fruit juice is based on the numbers and kind of microorganisms present, which was assessed by standard plate count method for the enumeration of total bacteria, fungi and coli forms in the sample.

The number of organisms (total bacteria and fungi) per gram of sample was calculated by using the formula given below.

$$
\text { Number of CFU per gram of the sample }=\frac{\text { Mean number of Cfu's x Dilution factor }}{\text { Quantity of sample on weight basis }}
$$

\section{E. Microwave treatment}

Sterilization of fruit juices by microwave technology use electromagnetic waves that are passing through the food and causes molecules to vibrate and result in generation of heat. The apple juice samples were subjected to microwave treatment in order to kill the microorganisms present in it. A domestic microwave oven was used for the sterilization purpose which has a frequency of $2450 \mathrm{MHz}$.

\section{F. Optimization of parameters}

The microwave treatment is highly dependent on the time and power level for which the food material is treated. In order to obtain maximum reduction in microbial population, time and power level of the microwave were optimized by conducting various trials. The treatment time was fixed as 20 , $40,60,80,100$ seconds and various power levels such as 180 , $300,450,600,900 \mathrm{~W}$ were used. The changes in number of microorganisms were noted for each exposure time and power level.

\section{G. Inactivation model}

The reduction in microbial count after treatment in microwave was studied. To develop a suitable inactivation model, the results were processed using GInafit software. The values were run on all the models out of which the suitable model was selected.

\section{H. Biochemical analysis}

To study the effect of microwave on the nutritional quality of the apple juice, the nutritional parameters such as total sugars, reducing sugars and total soluble solids concentration was tested before and after microwave treatment. Total and reducing sugars present in the sample were analyzed by Lane and Eynons titration method. The TSS content was determined using refractometer. Ascorbic acid content was estimated by titration against Indophenol dye [10].

\section{RESULTS AND DISCUSSION}

\section{A. Microbiological analysis of fresh apple juice}

Confirmation test for the presence of microorganism in the fresh apple juice was carried out using nutrient agar medium. It was observed that microbial colonies on the petri plate confirmed the presence of microbial contamination.

To identify the presence of E.coli and yeast in the test sample, selective media such as mac conkey and yeast glucose chloramphenicol agar were used. It was confirmed that the samples contained both E.coli and yeast (Table-I).

Table-I Microbiological analysis of fresh apple juice

\begin{tabular}{|c|c|c|}
\hline Dilution & E.coli & Yeast \\
\hline $10^{-1}$ & Above 300 & Above 300 \\
\hline $10^{-2}$ & 167 & 116 \\
\hline $10^{-3}$ & 43 & 49 \\
\hline $10^{-4}$ & Below 30 & Below 30 \\
\hline $10^{-5}$ & Below 30 & Below 30 \\
\hline
\end{tabular}

\section{B. Microbiological analysis of fresh apple juice}

Microwave assisted inactivation of E.coli and yeast

To study the effect of microwave treatment on the inactivation of E.coli and yeast in the petri plate, the operating parameters such as time of exposure at various power levels were used.

\section{i. Effect of exposure time on inactivation}

The inactivation of microorganisms at various exposure time of to microwave was studied and presented in Table-II and Figure 1. It was found that the number of colonies on the petriplates depend on the time for which the sample has been exposed to microwave treatment. The results showed that the E.coli cells were inactivated when exposed for a time duration of 80-100 seconds. However, there is a reduction in number of colonies from the $20^{\text {th }}$ second. The E.coli and yeast cells got inactivated at a time 100 and 60 seconds, respectively. It is clearly evident from the results that the inactivation increased as the exposure time of microwave increased which confirmed the results of Vadivambal et al.(2007) [11] on wheat disinfestation using microwave.

Table-II Number of colonies at different duration of exposure in Microwave

\begin{tabular}{|c|c|c|}
\hline Time(s) & E.coli & Yeast \\
\hline 20 & 103 & 51 \\
\hline 40 & 86 & 12 \\
\hline 60 & 58 & 0 \\
\hline 80 & 8 & 0 \\
\hline 100 & 0 & 0 \\
\hline
\end{tabular}

Published By: 


\section{Time optimization}

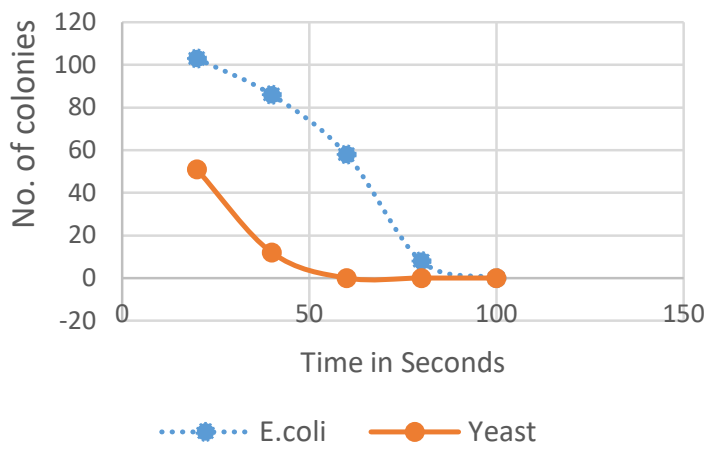

Fig.1. Inactivation Kinetics of E.coli and yeast with time

\section{ii. Optimization of power level}

The inactivation profile of E.coli and Yeast cells were performed at different power levels (180-900W) for the optimized time of exposure ( E.coli- $100 \mathrm{~s}$ and yeast- $60 \mathrm{~s}$ ) with respect to the number of colonies. It was observed from the Table-III and Figure 2 that the power level required for the inactivation of E.coli and yeast cells were $900 \mathrm{~W}$ and 450 $\mathrm{W}$, respectively. This is mainly due to the fact the increase in power level results in increase in temperature which enabled the inactivation of microorganisms and confirmed the results of Kozempel et al. (1998) [12]. It was concluded from many researches that the microbial inactivation is mainly due to thermal effect rather than non-thermal method [13], [14].

Table-III Number of colonies with variation in power level

\begin{tabular}{|c|c|c|}
\hline Power (Watts) & E.coli & Yeast \\
\hline 180 & 12 & 15 \\
\hline 300 & 4 & 2 \\
\hline 450 & 2 & 0 \\
\hline 600 & 2 & 0 \\
\hline 900 & 0 & 0 \\
\hline
\end{tabular}

\section{Power optimization}

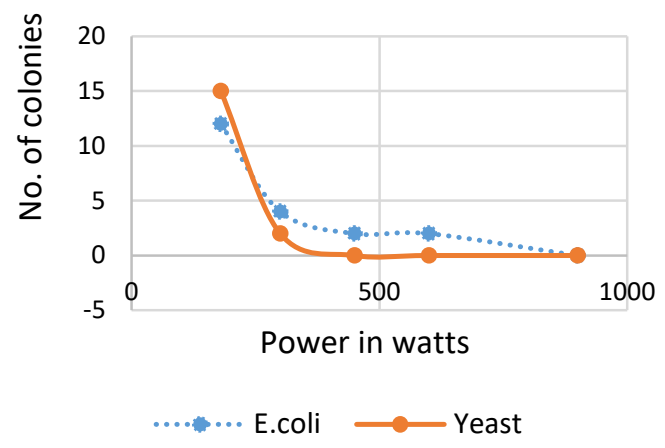

Fig.2 Inactivation kinetics of E.coli and Yeast with power level

\section{Inactivation model using GInafit software}

\section{i. Model for E.coli vs Power level}

The inactivation model for E.coli vs Power level is depicted in Figure 3. GInafit software contains different models for inactivation of microorganisms. Each model is specific with its own principle and formula. The R-square value close to 1 is considered as the best model for the given data. Among the 10 models Weibull model fits best for E.coli vs power level as its R-square value is 0.9657 which is the highest among the all the other models [15].

\section{ii. Model for Yeast Vs Power level}

For the yeast Vs power level (Figure 4) among the all 10 models in the software, Double Weibull model fits the best with a $R^{2}$ value of 0.999 which is very much close to 1 . The obtained results were similar to the results of Corcier et al.(2006) [16].

\section{iii. Model for E.coli vs Time}

The model fitting for E.coli vs Time is shown in Figure 5. For the E.coli Vs time, among the all 10 models in the software Weibull model fits the best with a $\mathrm{R}^{2}$ value of 0.9998 which is very much close to 1 . This model coincided with the results of Mafart et al.(2002) [15].

\section{iv. Model for Yeast Vs time}

The model for Yeast Vs time was fitted for all 10 models in the software (Figure 6). From the results it was found that Double Weibull model fits the best with a $\mathrm{R}^{2}$ value of 1 . The results were found to be in line with the research work of Corcier et al.(2006) [16].

\section{Nutrient analysis for the optimized parameters}

To ensure that microwave has no effect on nutrient content of the apple juice the total and reducing sugars, total soluble solids and ascorbic acid level is given Table-IV. There was significant change in the sugar content before and after treatment. But the ascorbic acid concentration was reduced after microwave treatment.

Table-IV Nutrient content before and after microwave treatment

\begin{tabular}{|l|c|c|}
\hline \multicolumn{1}{|c|}{ Nutritional content } & $\begin{array}{c}\text { Before } \\
\text { treatment }\end{array}$ & $\begin{array}{c}\text { After } \\
\text { treatment }\end{array}$ \\
\hline Total Sugars (g/l) & 116.2 & 114.9 \\
\hline Reducing sugars(g/l) & 24.8 & 23.2 \\
\hline Total soluble solids(\%) & 12.6 & 12.6 \\
\hline Ascorbic acid(mg/100ml) & 5.85 & 1.09 \\
\hline
\end{tabular}

\section{CONCLUSION}

Microwave is a significant method of thermal inactivation of microorganisms in food. The apple juice collected from fresh fruit juice shops around Karunya University was subjected to microwave assisted sterilization. From the results, it was found that the juice was contaminated with E.coli and yeast in significantly. Considerable reduction in the number of microorganisms was observed after the microwave treatment. E.coli was found to be completely inactivated at 90-100 seconds and 900W power level. Yeast was inactivated completely at 50-60 seconds and 450W power level. Weibull and double Weibull models were found to be the best suitable inactivation model with $\mathrm{R}^{2}$ values close to 1 for E.coli and yeast against both time and power level. The results also revealed that there was no significant loss in the total sugars, reducing sugars, total soluble solids concentration after the microwave treatment. The ascorbic acid content decreased after the microwave treatment. 


\section{Microwave Assisted Batch Sterilization of Apple Juice}

As the contamination level in the freshly prepared juice is significantly high, proper prevention should be taken for preparation, preservation and storage of the apple juice.

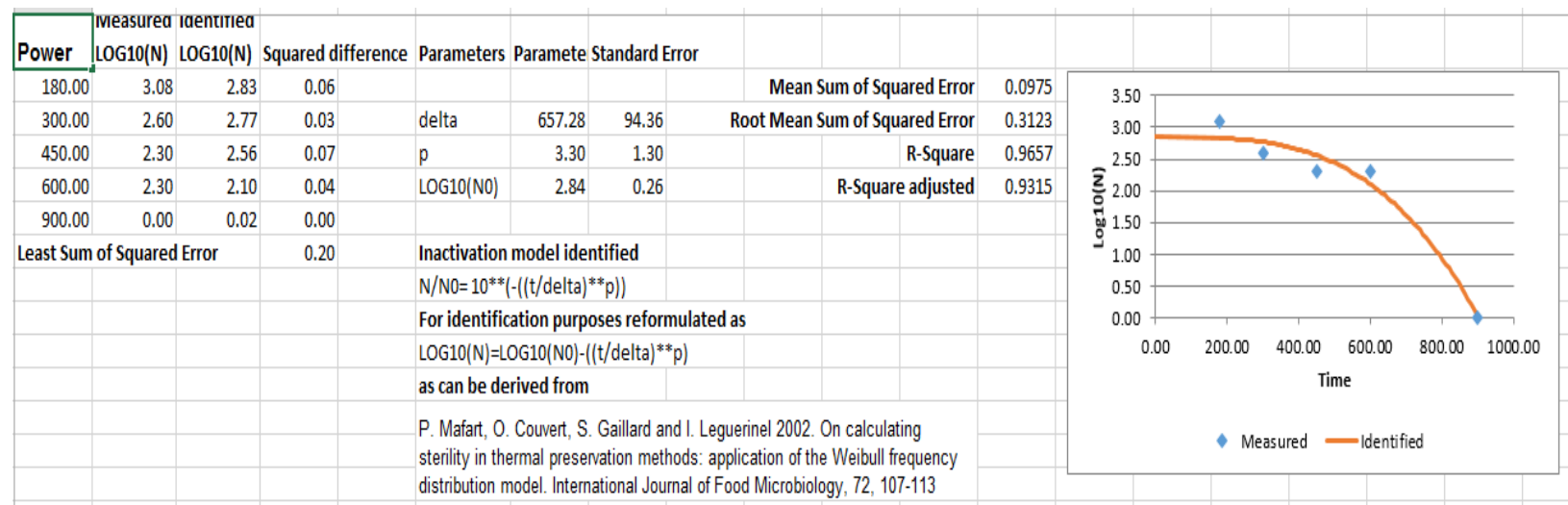

Fig. 3 Weibull model for E.coli Vs Power level

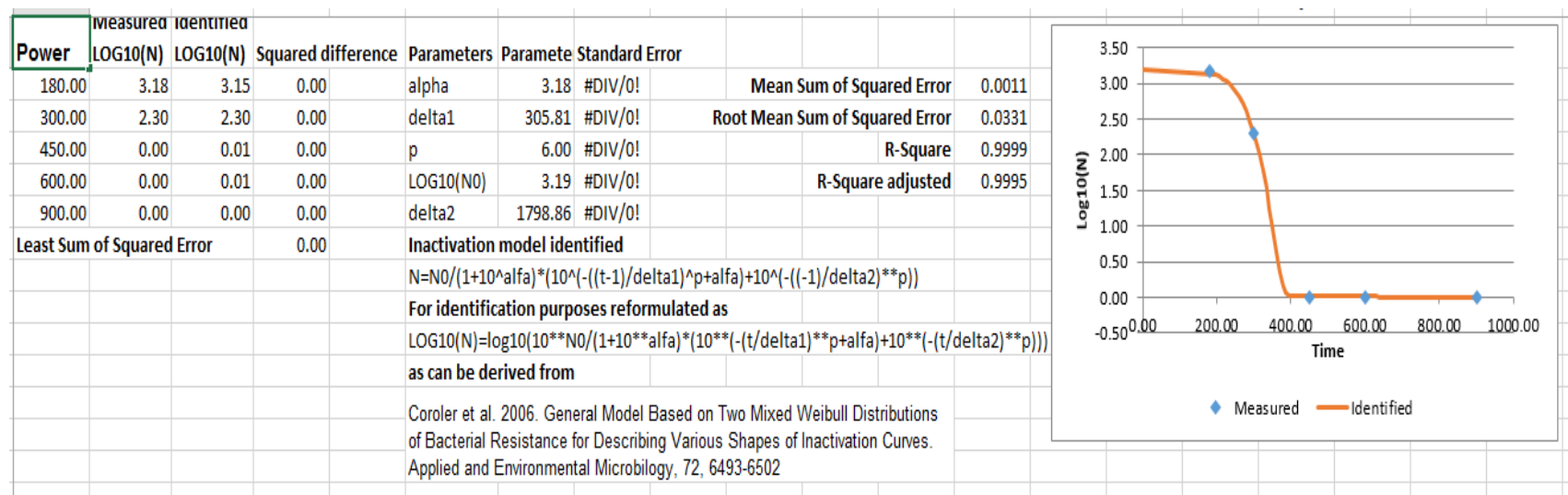

Fig. 4 Double Weibull model for Yeast vs Power level

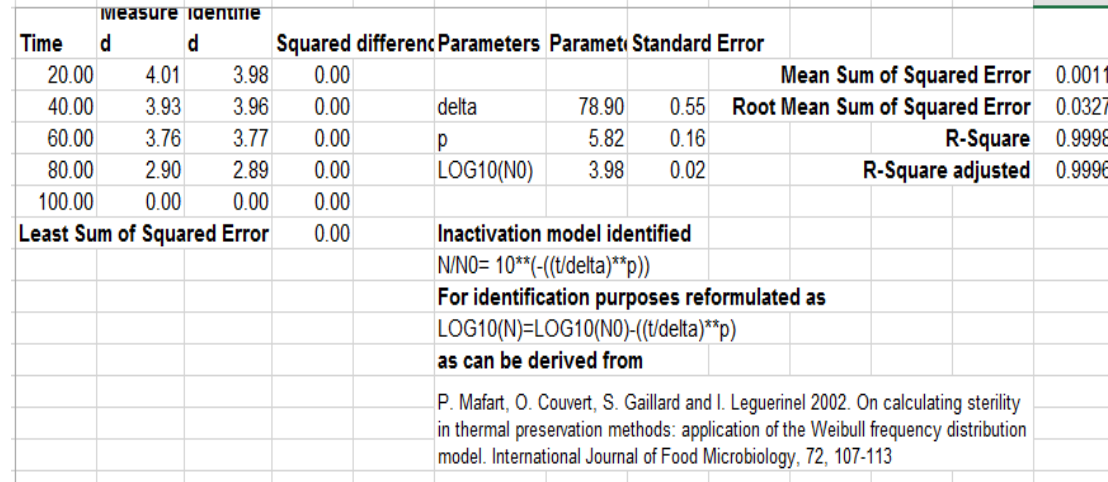

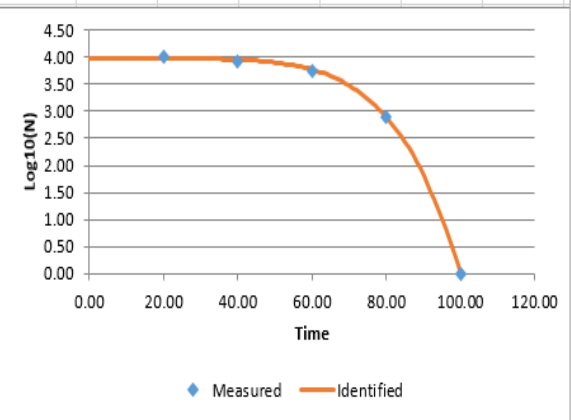

Fig. 5 Weibull model for E.coli Vs time

\begin{tabular}{|c|c|c|c|c|c|c|c|c|c|c|}
\hline Time & $\begin{array}{l}\text { Iveasurea } \\
\text { LoG10(N) }\end{array}$ & $\begin{array}{l}\text { Identirlea } \\
\text { LOG10(N) }\end{array}$ & Squared difference & Parameters & Paramete & Standard & & & & \\
\hline 20.00 & 3.71 & 3.70 & 0.00 & alpha & 3.71 & \#DIV/0! & & \multicolumn{2}{|c|}{ Mean Sum of Squared Error } & 0.0001 \\
\hline 40.00 & 3.08 & 3.08 & 0.00 & delta1 & 43.18 & \#DIV/0! & & \multicolumn{2}{|c|}{ Root Mean Sum of Squared Error } & 0.0076 \\
\hline 60.00 & 0.00 & 0.00 & 0.00 & $\mathrm{p}$ & 6.00 & \#DIV/0! & & & R-Square & 1.0000 \\
\hline 80.00 & 0.00 & 0.00 & 0.00 & LOG10(N0) & 3.71 & \#DIV/0! & & & R-Square adjusted & 1.0000 \\
\hline 100.00 & 0.00 & 0.00 & 0.00 & delta2 & 242.76 & \#DIV/0! & & & & \\
\hline \multicolumn{3}{|c|}{ Least Sum of Squared Error } & 0.00 & \multicolumn{3}{|c|}{ Inactivation model identified } & & & & \\
\hline & & & & \multicolumn{6}{|c|}{$\mathrm{N}=\mathrm{N} 0 /\left(1+10^{\wedge} \text { alfa }\right)^{*}\left(10^{\wedge}\left(-((\mathrm{t}-1) / \text { delta1 })^{\wedge} \mathrm{p}+\right.\right.$ alfa $\left.)+10^{\wedge}\left(-((-1) / \text { delta } 2)^{* *} \mathrm{p}\right)\right)$} & \\
\hline & & & & \multicolumn{5}{|c|}{ For identification purposes reformulated as } & & \\
\hline & & & & \multicolumn{7}{|c|}{ LOG10(N) $=\log 10\left(10^{* *} \mathrm{~N} 0 /\left(1+10^{* *} \text { alfa }\right)^{*}\left(10^{* *}\left(-(\mathrm{t} / \mathrm{delta} 1)^{* *} \mathrm{p}+\mathrm{alfa}\right)+10^{* *}\left(-(\mathrm{t} / \mathrm{delta} 2)^{* *} \mathrm{p}\right)\right)\right.$} \\
\hline & & & & \multicolumn{3}{|c|}{ as can be derived from } & & & & \\
\hline & & & & \multicolumn{6}{|c|}{$\begin{array}{l}\text { Coroler et al. 2006. General Model Based on Two Mixed Weibull Distributions } \\
\text { of Bacterial Resistance for Describing Various Shapes of Inactivation Curves. } \\
\text { Applied and Environmental Microbilogy, } 72,6493-6502\end{array}$} & \\
\hline
\end{tabular}

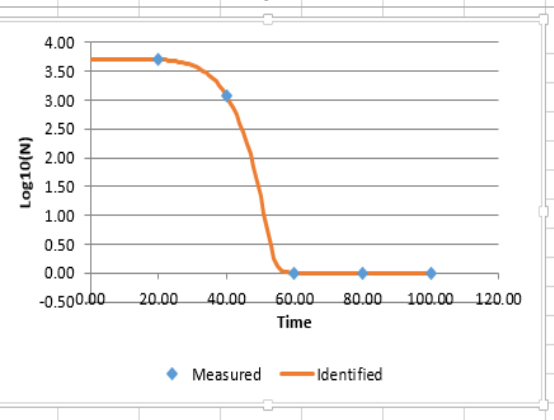

Fig. 6 Double Weibull model for Yeast Vs Time

Retrieval Number: L33241081219/2019@BEIESP

DOI:10.35940/ijrte.L3324.118419

Journal Website: www.ijitee.org
Published By:

Blue Eyes Intelligence Engineering \& Sciences Publication 


\section{REFERENCES}

1. Abe, D.K. and Blank, M. Guest editorial. The tenth special issue on high-power microwave generation. IEEE Transactions on Plasma Science, 32(3 ), 2004, pp.835-837.

2. Morrissey, J.J. Radio frequency exposure in mobile phone users: Implications for exposure assessment in epidemiological studies. Radiation Protection Dosimetry, 123(4), 2007, pp. 490-497.

3. Decareau, R. V. Microwave food processing equipment throughout the world. Food Technology, 40(6), 1986, pp. 99-105.

4. Venkatesh, M. S, and Raghavan, G. S. V. An overview of microwave processing and dielectric properties of agri-food materials. Biosystems Engineering, 88(1), 2004, pp. 1-18.

5. Kozempel, M., Cook, R. D., Scullen, O. J. and Annous, B. A. Development of a process for detecting nonthermal effects of microwave energy on microorganisms at low temperature. Journal of Food Processing and Preservation, 24, 2000, pp. 287-301.

6. Mudgett, R. E. Electrical properties of foods in microwave processing. Food Technology. 36, 1982, pp. 109-115.

7. Copson, D. Microwave heating. AVI Publishing Co., Westport, CT. 1962.

8. Romano, V.R., Marra, F. and Tammaro, U. Modelling of microwave heating of foodstuff: study on the influence of sample dimensions with a FEM approach. Journal of Food Engineering, 71(3), 2005, pp. 233-241.

9. Geedipalli, S.S., Rakesh, V. and Datta, A.K Modeling and heating uniformity contributed by rotating turntable in microwave oven. Journal of Food Engineering. 82, 2007, pp. 359-368.

10. AOAC. Association of Official Analytical Chemists. Official Methods of Analysis. $17^{\text {th }}$ ed., 2000.

11. Vadivambal, R, Jayas, D.S and White, N.D.G. Wheat disinfestation using microwave energy. Journal of Stored Products Research, 43(4), 2007, pp. 508-514.

12. Kozempel M.F., Bassam, A Richard, D, Cook, O., Scullen, J and Richard, C.W. Inactivation of Microorganisms with Microwaves at Reduced Temperatures. Journal of Food Protection, 61(5), 1998, pp. 582-585

13. Rosenberg, U. and Bogl, W. Microwave pasteurisation, sterilization, blanching and pest control in the food industry. Food Technology, 41, 1987, pp. 92-99.

14. Knutson, K. M., Marth, E. H. and Wagner, M. K. Microwave heating of foods. Lebensm Wiss Technology, 20, 1987, pp. 101-110.

15. Mafart, P., Couvert, O., Gaillard, S and Leguerinel, I. On Calculating sterility in thermal preservation methods: application of the Weibull frequency distribution model. International Journal of Food Microbiology, 72, 2002, pp. 107-113.

16. Coroler, L., Leguerinel, I., Mettler, E., Savy, N and Mafart, P. General Model Based on Two Weibull Distributions of Bacterial Resistance for Describing Various Shapes of Inactivation Curves. Applied and Environmental Microbiology, 2006, 72, pp. 6493-6502.

\section{AUTHORS PROFILE}

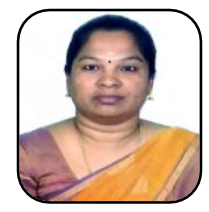

Dr.M.M.Pragalyaashree is currently working as Assistant Professor in the Department of Food Processing Technology, Karunya Institute of Technology and Sciences, Coimbatore, India. She has completed her Ph.D in Agricultural Processing and Food Engineering at Tamilnadu Agricultura University, Coimbatore during 2014. She has totally 5 years of teaching and research experience and published more than 15 research papers in National/International journals and conferences. Her area of specialization is MAP, cold plasma technology and extraction of bioactives from plant sources.

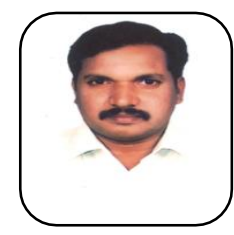

Dr.D.Tiroutchelvame is currently working as Assistant Professor in the Department of Food Processing Technology, Karunya Institute of Technology and Sciences, Coimbatore, India. He has completed his Ph.D in Technology at Anna University, Chennai during 2017. He has totally 23 years of teaching and research experience and published more than 14 research papers in National/International journals and conferences. His area of specialization is drying and dehydration of fruits and vegetables, osmotic dehydration and packaging technology. 